\title{
As Contribuições dos Psicólogos para o Matriciamento em Saúde Mental
}

\author{
Alexandra Iglesias \\ Universidade Federal do Espírito Santo, ES, Brasil.
}

\author{
Luziane Zacché Avellar \\ Universidade Federal do Espírito Santo, ES, Brasil.
}

Resumo: Objetivou-se neste estudo investigar as concepções do psicólogo da atenção básica sobre o apoio matricial em saúde mental e as consequentes repercussões de tais entendimentos para sua prática neste nível de atenção, em uma realidade municipal em que se optou por inserir psicólogos em $100 \%$ de suas Unidades de Saúde (US) e por afirmar o matriciamento em saúde mental partindo apenas dos Centros de Atenção Psicossocial (CAPS). Para tanto, foi selecionada uma US de cada uma das seis regiões de saúde do município e realizada entrevista semiestruturada com o psicólogo de cada uma delas, totalizando seis participantes de pesquisa. A pesquisa se utilizou da abordagem qualitativa e da técnica de Análise de Conteúdo de Bardin. São várias as concepções trazidas sobre o matriciamento em saúde mental: prática exclusiva da Psicologia; estratégia envolta a hierarquias e cobranças; proposta favorável ao compartilhamento entre equipes. A partir desses entendimentos compartilhados pelos profissionais de saúde, alguns psicólogos apresentaram dificuldades em afirmar outra prática que não aquela voltada ao atendimento ambulatorial individual, mas também outros conseguiram estabelecer parcerias diversas para o cuidado em saúde, a partir da concepção de que este trabalho requer compartilhamento de saberes, para uma atuação voltada à integralidade.

Palavras-chave: Atuação do psicólogo, Saúde Mental, Apoio Matricial, Integralidade em Saúde.

\section{The Psychologist's Contribution to the Matrix Support in Mental Health}

\begin{abstract}
With this study we set to investigate the primary care psychologist's conceptions on the mental health Matrix Support and the consequent repercussions of such conceptions to his practice at this level of attention, in a municipal context where there are psychologists in all primary care units, and where the mental health Matrix Support only begins at the psychosocial care centers ("CAPS"). To reach our objectives, we selected a Health Unit of each one of the six health regions of the city, and conducted semi-structured interviews with each psychologist, totalizing six interviews. The research used a qualitative approach and the Bardin's content analysis technique. With the interviews, we apprehended that there are several different definitions of the mental health Matrix Support, seen as: an exclusive practice of the psychologist; a hierarchical strategy to step up orders; or a proposal that facilitates the sharing between the teams. Some psychologists experienced difficulties differentiating Matrix Support from individual outpatient care, while others managed to establish several partnerships for health care, from the understanding that this work requires knowledge sharing that produces a performance directed to integrality.
\end{abstract}

KeYwords: Psychologist Performance, Mental Health, Matrix Support, Integrality in Health. 


\section{Las contribuciones del Psicólogo para el Apoyo Matriz en Salud Mental}

Resumen: El objetivo de este estudio fue investigar las concepciones que el psicólogo de la atención primaria de salud tiene con respecto al Apoyo Matriz en Salud Mental y las repercusiones de esas concepciones en su práctica en este nivel de atención, en una realidad municipal en la que hay psicólogos en el $100 \%$ de las Unidades de Salud (US), y en la que el Apoyo Matriz comienza solo a partir de los Centros de Atención Psicosocial (CAPS). Para esto, fue seleccionada una US de cada una de las seis regiones de salud del municipio y fue realizada una entrevista semiestructurada a un psicólogo de cada una de ellas, llegándose a un total de seis entrevistas. La investigación utilizó el enfoque cualitativo y la técnica de análisis de contenido de Bardin. El Apoyo Matriz es entendido de diferentes maneras por los psicólogos: como práctica exclusiva de la psicología; como jerarquía de saber/poder; o como propuesta que facilita el compartir entre equipos. Algunos psicólogos presentaron dificultades en diferenciar el Apoyo Matriz de la atención ambulatoria individual, mientras que otros lograron establecer diversas relaciones para alcanzar el cuidado en salud, entendiendo que este trabajo requiere un compartir de saberes que conduzca a la integralidad.

Palabras clave: Actuacion del Psicologo, Salud Mental, Matriz de Soporte, Integralidad en Salud.

\section{Introdução}

O Sistema Único de Saúde (SUS) tem se estruturado a partir dos ideais da integralidade, intersetorialidade, equidade, universalidade e participação social a fim de co-construir uma rede de cuidado favorável à promoção à saúde. Neste contexto, a atenção básica assumiu o papel de organizadora deste sistema de saúde, uma vez que sua proximidade com o território e com o usuário que o habita beneficia o conhecimento das necessidades daquela população e a luta contínua e compartilhada pelas condições favoráveis à saúde.

Dessa forma, pode-se afirmar que a atenção básica trabalha com um conjunto maior de questões quanto à saúde, imersas em um contexto igualmente mais amplo, o que exige deste nível de atenção articulação constante entre os diversos atores sociais, setores da sociedade e níveis de atenção à saúde, a fim de garantir a integralidade do cuidado que se almeja (Araújo, \& Carreteiro, 2001; Figueiredo, 2006; Romanholi, 2004; Starfield, 2002; Teixeira, 2005).

Vale destacar que compartilhamos os sentidos trazidos por Mattos (2006) sobre integralidade, que se refere à ampliação do olhar do profissional de saúde em sua relação com o usuário, de modo a atentar-se às necessidades em saúde presentificadas no território, para além daquelas ligadas à doença, trabalhando assim pela não fragmentação do sujeito. A integralidade referese também a atributos da organização dos serviços ao defender a articulação entre assistência e práticas de saúde coletiva. De qualquer modo, "quer tomemos a integralidade como princípio orientador das práticas, quer como princípio orientador da organização do trabalho, quer da organização das políticas, a integralidade implica uma recusa ao reducionismo, uma recusa à objetivação dos sujeitos" (Mattos, 2006, p. 61).

A integralidade trabalhada nesse estudo advoga por uma relação sujeito-sujeito, voltada à abertura para o diálogo com o outro, na construção conjunta de projetos de vida. Sendo assim, o matriciamento, dentre outras estratégias, surge como uma possibilidade de contribuir para a concretização destas parcerias necessárias ao cuidado integral, por meio do encontro entre duas ou mais equipes, atores e setores, com seus diferentes saberes e vivências, num processo de construção compartilhada, para a criação de práticas de cuidado contextualizadas com a realidade em questão, envolta aos seus aspectos sociais, culturais, políticos e econômico.

Além disso, o matriciamento constitui-se como uma importante estratégia de articulação de saberes para a construção contínua de conhecimentos outros que possam assegurar uma visão ampliada dos sujeitos - que não separa a saúde da saúde mental - de modo que eles passem a ser cuidados integralmente. Em outras palavras, o apoio matricial surge como arranjo organizacional potente para a formação em 
saúde de modo a integrar dialogicamente as distintas especialidades e profissões rumo a efetivação de uma clínica que se pretende ampliada (Campos, 1999, Campos, \& Domitti, 2007).

Neste contexto, o psicólogo inserido na atenção básica também tem sido requisitado a atuar a partir desta lógica de matriciamento, em detrimento de uma perspectiva individual-privatista, de modo a compartilhar seus saberes/práticas em saúde mental - principalmente no que se refere às suas referências de vínculo, acolhimento e escuta qualificada - para efetivar a integração destas práxis ao fazer de todo o profissional da área de saúde, independentemente de sua formação acadêmica, tendo em vista a transversalidade da saúde mental em qualquer prática de saúde. A transversalidade comparece como um princípio da Política Nacional de Humanização, que, ao contrário de uma perspectiva marcada por relações verticais de saber/poder, objetiva provocar uma desestabilização dessas fronteiras de saberes e territórios de poder na direção da construção de novos modos de se produzir saúde, mais ampliados e não serializados (Brasil, 2008; Pedroso, \& Vieira, 2009; Teixeira, 2005).

Como bem destaca o Ministério da Saúde, existe um componente de sofrimento subjetivo associado a toda e qualquer situação de adoecimento, o que significa dizer que todo problema de saúde é também - e sempre - de saúde mental, e que toda saúde mental é também - e sempre - produção de saúde (Brasil, 2005). Isso não acarreta em perda de especificidades do psicólogo, o qual não transmitiria aos demais profissionais da saúde o seu modo nuclear de intervir em saúde mental, por exemplo, mas atuaria para compor o campo de atuação em saúde com aqueles conhecimentos indispensáveis à ampliação da resolutividade do setor - juntamente a outros saberes disponibilizados também pelas demais categorias profissionais - investindo assim na possibilidade concreta de efetivação da integralidade do cuidado. Nesse sentido, o psicólogo da atenção básica pode contribuir neste trabalho de apoio matricial compartilhando a abordagem da clínica psicossocial, que considera o usuário como sujeito social, ao enfatizar sua subjetividade, corporalidade, historicidade, na construção das ações em saúde. Isso significa dizer que as ações em saúde passam a ser sustentadas em relações dialógicas entre profissionais e usuários, que assim construídas passam a fazer sentido para a vida daquele sujeito-usuário, ampliando sua efetividade (CFP, 2009).

Neste sentido, não cabe uma atuação inspirada em um modelo médico - como historicamente a prática psicológica tem se presentificado no sistema público brasileiro - que se pauta em uma perspectiva clínica-individualista, privatista e curativa-assistencial, a qual trabalha, muitas vezes, com um sujeito idealizado e descontextualizado, na direção de adaptá-lo à ordem social vigente (Dimenstein, 2001; Ferreira Neto, 2008; 2010; Freire, \& Pichelli, 2010; Spink, 2007). A lógica do apoio matricial requer do psicólogo da atenção básica uma disponibilidade em compor uma equipe interdisciplinar - o que significa também permitir que o seu saber possa ser discutido e até questionado, a partir da necessidade e do desejo do usuário - bem como, um desprendimento, tanto no que diz respeito a sua abertura para a experimentação de outras atuações construídas no encontro, quanto à disponibilização do seu conhecimento ao outro, o qual, a partir do contato com este saber, pode, por exemplo, dar conta de melhorar sua relação com o usuário, qualificando sua escuta e potencializando suas práticas (Spink, 2007).

Defendemos que tal compromisso do psicólogo da atenção básica se faz ainda mais necessário se considerarmos o matriciamento em saúde mental partindo unicamente dos Centros de Atenção Psicossocial (CAPS), que certamente não possuem a mesma disponibilidade daquelas equipes especificamente voltadas a esta função de matriciar, para as articulações intersetoriais, interdisciplinares e comunitárias indispensáveis à efetivação do apoio em toda a sua potencialidade. Contudo, sustentar uma prática pautada na lógica do apoio matricial, quando inserido na atenção básica, parece não ser tão simples, tendo em vista a demanda de usuários e demais profissionais que se mantém bastante associada à lógica individual-privatista.

Diante de todas essas discussões, interessa-nos investigar as concepções do psicólogo da atenção básica sobre o apoio matricial em saúde mental e as consequentes repercussões de tais entendimentos para sua prática neste nível de atenção, em uma realidade municipal em que se optou por inserir psicólogos em $100 \%$ de suas Unidades de Saúde (US) e por afirmar o apoio matricial em saúde mental partindo apenas dos CAPS. 


\section{Método}

A coleta de dados desta pesquisa foi realizada no ano de 2013 em um município do sudeste do Brasil, o qual desde 2007 incluiu psicólogo em todas as suas Unidades de Saúde (na ocasião 28 US) e, no mesmo ano, iniciou o trabalho de apoio matricial em saúde mental partindo dos três CAPS que possui (CAPS álcool e drogas, CAPS II e CAPS infanto-juvenil). Este município está dividido em seis regiões de saúde, sendo que cada qual abrange um território específico, com realidades diversificadas.

Foi selecionada uma Unidade de Saúde de cada uma destas regiões, totalizando seis US, sendo que quatro delas funcionam na lógica da Estratégia de Saúde da Família (ESF) e as outras duas atuam como Unidades Básicas sem ESF. Para escolha destas Unidades, a pesquisadora selecionou aquelas com as quais mantinha menor contato no dia a dia de trabalho, já que a pesquisadora era servidora pública do município. A partir daí, foi realizada entrevista semiestruturada com o psicólogo que atua na Unidade, todos eles profissionais efetivados por meio de concurso público municipal. As seis entrevistas foram realizadas individualmente e gravadas em áudio após a devida autorização dos participantes, da Secretaria Municipal de Saúde, bem como do Comitê de Ética em Pesquisa. Seguiu-se com o procedimento de análise qualitativa dos dados, mais especificamente com a técnica de análise de conteúdo de Bardin (1988), que consiste em um conjunto de técnicas de análise das comunicações que visa obter indicadores que permitam a inferência de conhecimentos relativos às condições de produção/recepção destas mensagens.

\section{Resultados e discussões}

A partir das informações trazidas pelos psicólogos entrevistados, consideramos importante destacar, para alcançar os objetivos deste estudo, as versões sobre o que os demais profissionais de saúde das Unidades pensam acerca do apoio matricial, bem como as concepções trazidas por estes psicólogos sobre o matriciamento, para então trazermos a discussão sobre a atuação dos psicólogos da atenção básica na direção do apoio matricial e da integralidade do cuidado. A escolha por tal arrumação se deve ao fato de acreditarmos que a atuação do psicólogo da atenção básica, no que diz respeito às suas contribuições para a efetivação do apoio matricial, está intrinsecamente relacionada aos seus próprios entendi- mentos sobre o apoio, bem como às suas concepções acerca das percepções dos demais profissionais que compõem a atenção básica sobre matriciamento em saúde mental.

\section{As concepções dos psicólogos da atenção básica sobre o apoio matricial em saúde mental}

A partir da análise do material coletado foi possível destacar quatro grupos de entendimentos a respeito do apoio matricial por parte dos psicólogos inseridos na atenção básica, bem como algumas pontuações importantes sobre esta prática no cotidiano do serviço básico de saúde.

O primeiro entendimento associa o apoio matricial à concepção de compartilhamento de saberes e práticas para o cuidado em saúde. Nesta perspectiva, compareceram nas falas dos entrevistados as palavras: "troca", "integração dos trabalhos", "pensar e intervir em conjunto", “divisão de responsabilidade”, o que necessariamente, de acordo com os entrevistados, requisita também das equipes de referência (Unidades de Saúde) e das equipes de apoio (Centros de Atenção Psicossocial) uma relação baseada na "confiança" e no "vínculo".

Tal ideia corrobora a proposta primordial desta estratégia matricial, que apregoa a conquista de ações compartilhadas, interdisciplinares e integradas para a concretização da integralidade do cuidado. Para tanto, faz-se essencial a construção de relações de confiança e respeito entre os profissionais, de modo que o contato entre os diversos setores e atores, imprescindíveis neste cuidado, se estruture entre pessoas que acreditam na potencialidade do outro, na sua contribuição e no seu trabalho para um objetivo em comum: a promoção à saúde.

Nesse contexto de discussão, vale ressaltar a pontuação de alguns psicólogos de que se trata de um trabalho desafiador, que causa inúmeros incômodos e desconfortos, uma vez que ao se dispor estar com o outro no território, o profissional se depara com as mais variadas questões de sofrimento e realidades sociais, que extrapolam sua governabilidade de ação.

É incômodo matriciar. É muito incômodo sair do seu lugar de conforto e ir para a rua. Ir ao território significa você se deparar com a angústia, porque você encontra os casos, se sente impotente, "o que eu faço com isto agora?" 
Não tem isto, não tem aquilo, você coloca o pé na lama, então causa angústia. É entrar nos buracos todos, entrar nas casas, ter contato com o tráfico, os cheiros, as vielas, os becos, sujeira, maus tratos, desgraça. Então você vê isto com muita constância e isto angustia, então tem resistência a isto (Profissional 1).

Consideramos que todos estes incômodos estão intrinsecamente relacionados também a uma história marcada pela compartimentalização dos serviços, setores e sujeitos, os quais, isoladamente, tentam executar o que lhes cabe na resolução de problemas, que são da ordem do coletivo. Ou ainda, no caso do setor saúde, uma lógica de ação marcada por um livre fluxo de encaminhamento, transferência de responsabilidade, afirmações de certezas, disputas entre o saber médico e o não médico, que obstaculizam qualquer atuação efetivamente conjunta. Não podemos desmerecer a importância dos incômodos na provocação de mudanças, mas acreditamos que a governabilidade sobre uma situação-problema somente se efetiva a partir de ações coletivas, que podem acontecer por meio do apoio matricial, desde que não seja tomado, assim como outras estratégias já o foram, como onipotente no propósito de promoção à saúde. Nas palavras de um dos entrevistados:

A ideia do apoio é esta e a gente conseguir conversar abertamente, dizer que não está legal, que a gente poderia propor de outra forma, de pensar quais são as possibilidades que a gente pode trazer para pensar, para discutir, para pensar isto. Ninguém no lugar de saber. Não tem mais hierarquia de saber, "porque nós somos do CAPS e assim que tem que ser". Diferentemente, todo mundo se dispõe, pensando assim, o que a gente pode pensar sobre este caso, assim esgota tudo, agente de saúde, todo mundo em nível igual. Então é pensar junto, igual fazer um brainstorm junto do caso, embora tenha pessoas com saberes específicos, mas a gente sempre tem perguntas. Assim a gente cuida de verdade (Profissional 1).

Nessa perspectiva, as relações hierárquicas de saber-poder, predominantes entre generalistas e especialistas, por exemplo, em que, geralmente, este último dita ao outro o que deve e não deve ser feito, podem dar lugar a relações de corresponsabilidade, na qual os envolvidos se dispõem igualmente a contribuir com seus saberes singulares na composição de um cuidado que se pretende integral. Como assinala Campos (1999), o apoio matricial tem também essa função de produção de novos padrões de inter-relações entre os vários atores sociais para promoção à saúde, que por sua vez, somente se efetiva na integração dialógica entre os distintos saberes e práticas existentes na sociedade.

Todavia, compareceram também enunciações que falam de relações marcadamente conflitantes entre apoiadores dos CAPS e equipes de referência, subjacentes ao segundo entendimento do matriciamento como relativo a uma hierarquia de saberes - que, portanto, deve ser feito por profissionais que sabem mais que outros - o qual resulta, na prática, em um 'jogo de empurra' do usuário de um serviço a outro, ao contrário de um encontro efetivamente voltado a se pensar projetos de cuidado integrados, como na fala de um dos psicólogos:

Quem faz o matriciamento de saúde mental não é quem sabe muito, é quem sabe até menos. Aí, às vezes, aparece querendo devolver. É mais uma negociação, é meu, é seu, este fica com você, empurrando. Olha, tem um caso muito grave, aí vem com aquela resposta toda gravada, pronta: "tem que vê se é..." Eu disse: "olha, já teve intervenção da médica, eu tive lá com a ACS, veio aqui, nós fizemos isto, aquilo, é um transtorno grave sim, por causa disto e disto”. “Não então...”. As pessoas se defendem. Não têm encontros frequentes. Fica só apagando incêndio. Além disto, eles falam muitas regras, tipo assim, "vocês já fizeram isto? Já fizeram aquilo? Por que senão a gente não vai. A gente não precisa ir se vocês não fizeram a parte de vocês" e quando a gente faz a nossa parte, a gente não precisa deles (Profissional 2).

Prevalece, nesse caso, uma relação de disputa entre quem sabe mais e menos, bem como uma fragmentação dos usuários - "é meu, é seu, este fica com você, empurrando" - e dos serviços, já que cada qual tem sua parte a cumprir. A troca, o compartilhamento, o encontro, a relação baseada no vínculo e na confiança - presente no plano do ideal desta proposta - não acontecem; traduz-se uma relação 
conflitante e distante, baseada em uma hierarquia de saber/poder entre estes atores da saúde, sendo que ambos não conseguem se ouvir para pensar juntos, estratégias de cuidados pertinentes àquela realidade. Prepondera, neste caso, como nos traz Stotz e Araújo (2004), uma visão de mundo que nega a história, o saber e as vivências dos sujeitos para a construção de alternativas de cuidado integral. Sendo assim, destacamos a importância de se problematizar estas relações, para que em nome de uma estratégia politicamente correta, como o apoio matricial, não acabemos, na prática, por reproduzir uma lógica de que existem os que sabem mais e que, portanto, estão autorizados a ditar as regras; e aqueles que devem cumpri-las.

Um terceiro entendimento trazido pelos psicólogos da atenção básica entrevistados associa o apoio matricial à possibilidade de aproximação com as especialidades, mais especificamente com a atenção psiquiátrica, o que, segundo os entrevistados, facilita o processo de "encaminhamento" e "marcação de consulta". Neste sentido, um dos psicólogos afirmou requisitar o apoio matricial em saúde mental ofertado pelos CAPS apenas quando possui um caso para encaminhar ao psiquiatra ou a estes serviços.

Ainda a partir da perspectiva do matriciamento enquanto possibilidade de aproximação com a especialidade, um psicólogo pontuou a necessidade de realização de um matriciamento diferenciado para médicos e não médicos, sob a justificativa de interesse da categoria médica apenas pelo aspecto psicofarmacológico em saúde mental: "Não tem matriciamento para os médicos, discussão de casos de médico para médico e eu acho que é necessário. Não tem de psicólogo para psicólogo? Por que não para o médico? Saúde mental tem prescrição de medicamento, tem que ter e é isto que interessa a ele" (Profissional 3).

$\mathrm{O}$ apoio matricial certamente traz esta possibilidade de aproximação com as especialidades - no que diz respeito a sua proposta teórica - com a finalidade de favorecer uma construção dialógica para o cuidado integral em saúde mental. Neste cuidado integral não se pode perder de vista que o saber médico e o conhecimento a respeito dos psicofármacos também fazem parte das necessidades de cuidado das pessoas em sofrimento psíquico. Assim, não diríamos de um apoio para cada categoria profissional, mas de contemplarmos também estas necessidades médicas nas discussões promovidas pelo matriciamento para a atenção psicossocial; ao contrário, corremos um grande risco de sustentarmos uma mesma lógica de supremacia de um saber a outro. A promoção à saúde mental se faz nas múltiplas conexões possíveis à realidade de cada sujeito, considerando suas questões biológicas, culturais, políticas, econômicas, sociais.

Ainda em relação a este terceiro entendimento trazido pelos entrevistados, pode-se argumentar que esta concepção de matriciamento - quando limitada a uma aproximação para a marcação e encaminhamento - aponta para uma potencial dificuldade de acesso aos serviços e a outros profissionais de saúde, por exemplo, de modo que os profissionais da atenção básica precisam de se utilizar do apoio matricial para a marcação de consultas e encaminhamentos. Contudo, é certo que até mesmo nesta lógica - matriciamento para marcação e encaminhamento - há a possibilidade de se promover encontros entre serviços, setores e atores, que ao "passar o caso do usuário", como dito pelo psicólogo, podem ter seus modos de operar em saúde modificados pela aproximação de saberes diversos.

Um quarto entendimento trazido pelos psicólogos da atenção básica destaca o apoio matricial como sinônimo de "discussão de caso" e "supervisão", neste caso, os psicólogos acrescentam a possibilidade de, a partir daí, "capacitar" e "orientar" o profissional no cuidado em saúde mental, principalmente aqueles que não dispõem de uma formação voltada à abordagem psi. Acrescido disto, ainda nesta perspectiva, um dos entrevistados pontuou a contribuição deste matriciamento a partir da discussão de caso, no conhecimento das pessoas em sofrimento psíquico pelos profissionais das Unidades de Saúde, as quais, antes deste trabalho, eram desconhecidas por este serviço.

Consideramos importante destacar a inegável contribuição da discussão de casos para o processo de formação permanente e continuada de todos os envolvidos no debate; inclusive esta possibilidade de "capacitação" em serviço é anunciada pelo Conselho Federal de Psicologia (2009) como um dos objetivos do apoio matricial em saúde mental, disponibilizados pelos profissionais 'psi' à atenção básica, no propósito da escuta, acolhimento e manejo das vulnerabilidades psicossociais vivenciadas pela atenção básica junto à população adscrita. Contudo, não se pode perder de vista que a discussão de casos é uma das possíveis ferramentas utilizadas pelo matriciamento, que não deve ser confundida com o conceito de apoio 
matricial em si, o qual contribui com a saúde coletiva com pressupostos, possibilidades, instrumentos e objetivos variados pela garantia da integralidade da atenção em todo o sistema de saúde.

\section{As concepções dos psicólogos da atenção básica sobre o que os demais profissionais de saúde das Unidades pensam acerca do apoio matricial em saúde mental}

A partir dos dados coletados, foi possível apreender a existência de cinco grupos de entendimentos acerca do apoio matricial por parte dos profissionais da atenção básica, segundo a perspectiva dos psicólogos: 1) o desconhecimento do que seja o apoio; 2) o apoio como restritivo à Psicologia; 3) o apoio como uma proposta pouca resolutiva; 4) o apoio como uma estratégia envolta a hierarquias e cobranças e 5) o apoio como uma estratégia favorável à comunicação entre equipes diversas e ao acompanhamento dos casos de pessoas em sofrimento psíquico em sua integralidade.

Segundo alguns dos psicólogos entrevistados, existem, na Unidade, aqueles profissionais que simplesmente desconhecem o que seja a proposta de apoio matricial, uma vez que, por algum motivo, nunca tiveram contato com este trabalho.

Comparece também, conforme indicado por alguns dos entrevistados, na atenção básica, uma concepção, por parte dos demais profissionais, de que o apoio matricial em saúde mental é para a Psicologia, tendo em vista a ideia de que a "saúde mental é o psicólogo" (Profissional 4). Nestes casos, configura-se um cenário de não envolvimento afetivo, ideológico e profissional (Lourau, 2004) da maioria dos demais profissionais da equipe da atenção básica com os propósitos da saúde mental, o que tem prejudicado por consequência a efetivação da integralidade do cuidado. Esses profissionais não relacionam seus trabalhos à saúde mental, restringindo o contato dos apoiadores dos CAPS ao psicólogo da atenção básica. Nas palavras de um psicólogo:

É uma visão assim: 'isto não é para mim, isto não é comigo, meu trabalho é este, eu tenho que dar conta das técnicas, tenho que dar conta das vacinas'. Eu estou fazendo um trabalho e mostrando que não é só para mim o apoio. Saúde Mental é uma questão que abrange a
Unidade, não a psicóloga. Até as pessoas terem este pensamento demora um pouco, mas a gente vai tentando (Profissional 4).

Assim, este psicólogo afirma uma concepção fragmentada trazida pelos profissionais de saúde, de que cabe a cada um uma tarefa pré-determinada, além de uma perspectiva focada na técnica, o que pode repercutir negativamente para a invenção de outros modos de fazer saúde necessários - tendo em vista a diversidade das realidades territoriais e de sujeitos-usuários - que se efetiva a partir da disponibilidade do encontro interativo. Em outras palavras, a possibilidade de uma intervenção diferenciada a partir também da inclusão do profissional psicólogo na atenção básica, baseada em um trabalho integrado, intersetorial, voltado para a coletividade, fica prejudicada, uma vez que prevalece a dicotomia entre a competência técnica e a sensibilidade social, entre aquele profissional que trabalha com as questões da mente e do social e aquele que intervém em um corpo biologicamente adoecido (Camargo-Borges, \& Cardoso, 2005).

Essas dicotomias, assim como os paralelismos mente/corpo, subjetividade/objetividade, teoria/prática, saúde/saúde mental, insistem em separar realidades intrinsecamente relacionadas, que se constroem mutuamente, causando prejuízo à construção de um cuidado que se pretende integral. O mental está presente no processo saúde-doença. $\mathrm{E}$ aí não cabe, necessariamente, uma intervenção especializada da Psicologia; muitas vezes, são situações e eventos de vida geradores de estresse, que leva ao adoecimento deste sujeito-usuário, o qual pode se beneficiar de intervenções de apoio psicossociais ofertadas em especial por aquele profissional da atenção básica com o qual possui mais vínculo.

Todos os profissionais de saúde podem contribuir para este cuidado em saúde mental, tanto que, de acordo com a Organização Mundial de Saúde (OMS) e o Ministério da Saúde, quase $80 \%$ dos usuários encaminhados aos profissionais que trabalham especificamente com a saúde mental não trazem, a priori, uma demanda específica que justifique a necessidade de uma atenção especializada (Brasil, 2003). Desse modo, o psicólogo da atenção básica tem um papel importante também em afirmar, provocar e convocar todos os profissionais de saúde a trabalharem a partir da perspectiva de que todos podem e devem atuar 
pela saúde mental, corroborando assim a lógica de um sistema único de saúde que se fundamenta primordialmente no princípio da integralidade para a promoção à saúde.

Outra versão trazida pelos psicólogos entrevistados da atenção básica aponta que muitos profissionais de saúde das US percebem o apoio como uma "obrigação" de trabalho, com "pouca resolutividade e encaminhamentos", "chato", "repetitivo" e "desorganizado". Na fala de um dos psicólogos:

Sobre o matriciamento eu ouço sempre muitas críticas: "Ah, porque estas reuniões a gente tem que ir, mas a gente só fala dos mesmos casos e os casos nunca têm um encaminhamento, nunca têm uma resolutividade". "ah, este caso só tem jeito quando o paciente morrer, não tem nada para fazer". [...] Tem a questão dos profissionais da Unidade, mas tem também do matriciamento. Tem uma matriciadora que está aqui fazendo matriciamento há muitos anos, que traz um cansaço na sua fala: "A gente já tentou tantas coisas, de tantas formas e parece que não dá certo", repetindo a mesma fala da equipe, mas de outro lugar. Quando eu propus: "vamos fazer igual ao outro CAPS?", "Ah não, a gente já tentou isto e não deu certo", "tá, não deu certo, mas agora é outra equipe que está aqui, por exemplo, eu, muitas enfermeiras trocaram agora, tem outra matriciadora que também é nova". "Não" (Profissional 5).

Faz-se importante destacar - o que de certa forma comparece na percepção acima transcrita - os desafios do cuidado em saúde mental e a complexidade da existência-sofrimento. Estamos falando de um contexto marcado por anos de exclusão social, pela certeza da periculosidade e irrecuperabilidade destas pessoas em sofrimento psíquico, o que resultou em pouco ou nenhum investimento nestes indivíduos como sujeitos de direito. Diante de tal complexidade, podemos afirmar que não cabe a aplicação de procedimentos padronizados e/ou ações meramente técnicas por um ideal de cura em saúde mental; como bem destaca Rotelli (1990, p. 30), estas situações requerem a co-construção de projeto de "invenção de saúde" e de "reprodução social" destes sujeitos que vivenciam a existência-sofrimento, o que demanda do serviço e dos profissionais, necessariamente, disponibilidade para igualmente inventarem contínua e frequentemente propostas de cuidado diversas e compartilhadas. Contudo, é marcante ainda, no setor saúde, uma perspectiva de busca da cura, de um ideal de bem-estar, de respostas a todo e qualquer problema, que perpassa a formação de todos os profissionais da saúde e faz com que sejamos tão pouco tolerantes a aqueles casos, em que a mera aplicação da técnica não dá conta de resolvê-los, tamanha a sua complexidade, fazendo com que retornem reiteradamente ao serviço de saúde com a demanda de mais cuidado.

Nesse contexto, tendemos a reproduzir a ação de encaminhamento da situação, todavia, no que diz respeito à atenção básica, esta ação fica um tanto quanto limitada, já que aquele usuário habita naquele território, circula pelos espaços de abrangência da Unidade e tem seus problemas também relacionados ao cotidiano daquela comunidade; requisitando, portanto, recorrentemente a atenção das Unidades de Saúde. Nestas conjunturas, outro psicólogo entrevistado falou sobre sua atuação no sentido de minimizar algumas frustrações cotidianas dos profissionais de saúde trazidas pelo cuidado a estes casos mais complexos.

Quando eles estão demais desanimados, eu tento passar para os profissionais suportar um pouquinho desta frustração, porque os médicos, os enfermeiros, eles querem a evolução do paciente, eles querem que ele saia daquele lugar que ele está e vá para outro lugar ideal, que é o lugar que eles imaginam que a pessoa tem que estar e na verdade é muito difícil você conseguir isto de todas as pessoas, cada um tem seu lugar e às vezes o lugar dele não vai ser o meu nunca. Isto é difícil, mas eu acho que é uma coisa importante que o psicólogo tem a fazer (Profissional 6).

O psicólogo, como figura importante no campo da saúde mental, pode contribuir assim para a discussão, na perspectiva da Reforma Psiquiátrica, de mudança do foco da doença para o sujeito, o que remete a transformação no modo de operar neste setor na direção da reabilitação psicossocial. Com isso trabalha-se também pela promoção de autonomia, no sentido de contribuir para ampliação de possibilidades de relação destes sujeitos-usuário com a vida 
social em seu movimento. Para tanto, faz-se necessário ação, compromisso e responsabilidade de todos os profissionais rumo às conexões com os recursos da comunidade, serviços, setores e atores (Lussi, Pereira, \& Pereira Junior, 2006; Nicácio, 2003).

Outro entendimento trazido pelos profissionais da atenção básica sobre o matriciamento em saúde mental, segundo alguns dos psicólogos entrevistados, associa tal estratégia a "cobranças" e "hierarquias", em que os especialistas ditam o que os profissionais da Unidade devem fazer, de modo que assim, de acordo com alguns entrevistados, o matriciamento só acontece para cumprimento das metas de um programa existente neste município de incentivo ao desemprenho - "IDV" - que também garante um acréscimo remuneratório aos trabalhadores.

Umas das críticas que é feita ao matriciamento, que acaba que o apoio matricial veio como se fosse para reforçar o que a Unidade tinha que fazer, mas muito pouco verdadeiramente como um apoio. Trabalha-se muito mais para direcionar, colocando de cima para baixo do que de fato como um apoio. Aí entra em um ciclo, que faz a reunião porque tem que entrar na meta do IDV. É uma política nacional, então, tem que acontecer, mas não se pensa na especificidade do território, da necessidade dos casos e acaba voltando em uma discussão que é sabida por todo mundo, que tem que fazer vinculação no território, que tem que usar as ferramentas da estratégia de saúde da família, da saúde coletiva. É aquilo, se as pessoas não fizeram, elas sabem que tem que fazer e não se discute a especificidade do caso (Profissional 2).

Ainda na perspectiva do apoio enquanto "cobrança", segundo um dos entrevistados, "tem profissionais que tem um pouco de medo do matriciamento" (Profissional 5).

"Eles vem aqui me cobrar o que?", "o que eu fiz?”, “o que eu tinha que ter feito?”, “eu não sei nada desta pessoa". Aí eu digo: "tudo bem, vamos procurar saber, porque até o dia tal da reunião a gente tem que procurar saber, então você pergunta para a agente de saúde, se puder fazer uma visita, se souber de alguma coisa, você já fica alerta, porque a gente vai ter que conversar sobre ela" (Profissional 5).

Assim, parece prevalecer uma relação marcadamente hierarquizada e verticalizada, contrariando a perspectiva de um trabalho que se pretende fomentar a integração, o compartilhamento e a parceria para a superação dos inúmeros desafios que se apresentam no contexto da saúde coletiva. Neste sentido, vale colocar em análise esta prática, mais uma vez, na direção de problematizar a função do apoio matricial dentro do cenário da saúde coletiva: estamos tralhando pelo fortalecimento dos encontros para a potencialização dos sujeitos ou para a subjugação aos saberes especialistas?

Por outro lado, há profissionais, segundo os entrevistados, que de tanto participarem deste trabalho de matriciamento, reconhecem esta estratégia como favorável à comunicação entre equipes diversas e ao acompanhamento dos casos de pessoas em sofrimento psíquico em sua integralidade. "Então é engraçado, tem duas posturas, tem quem acha: 'que bom, então eles vão ajudar a gente' e tem quem acha: 'aí meu Deus, como assim, o que eles querem de mim'” (Profissional 5).

De qualquer modo, a chegada do apoio matricial em saúde mental parece ter deslocado estes profissionais das Unidades de seus lugares, por vezes baseados em procedimentos padronizados e encaminhamentos descompromissados pela continuidade do acompanhamento pela atenção básica. Em relação a isto, o Conselho Federal de Psicologia (2009) chama atenção para as transformações operadas pelo matriciamento nas equipes que, na medida em que são convocadas a trabalhar também pela saúde mental, passaram a se apropriar do tema e de problemas mais complexos apresentados pela população como um todo, aguçando sua escuta e seu olhar para as necessidades reais destas pessoas naquele território.

\footnotetext{
1. O Índice de Desempenho Variável (IDV) vinculado ao Programa de Melhoria do Acesso e da Qualidade do Serviço de Saúde do município consiste em uma estratégia para aperfeiçoar a organização dos serviços e setores da Secretaria de Saúde desse município por meio de avaliação das práticas de saúde com ênfase na capacidade de gestão, na condução do processo de trabalho, no monitoramento, controle e avaliação de todos os processos (Vitória, 2014, p. 4).
} 


\section{Os apoios matriciais em saúde mental: atuação dos psicólogos da atenção básica}

A partir destas versões a respeito do apoio matricial em saúde mental, foi possível apreender uma diversidade de atuações do psicólogo na atenção básica, de modo que não se pode afirmar uma ação profissional predominante entre os psicólogos deste município. Vale destacar que as concepções dos psicólogos entrevistados das duas Unidades Básicas que não funcionam na lógica da Estratégia de Saúde da Família (ESF), não necessariamente se diferenciaram dos entendimentos daqueles da ESF; todavia, foi bem marcado, por estes psicólogos das duas Unidades Básicas, uma maior dificuldade em efetivar um trabalho de apoio matricial, pelos entraves relativos à falta de encontros entre os próprios profissionais do serviço e a pouca proximidade com o território, o que, segundo eles, obstaculiza também a tentativa de trazer o usuário em sofrimento psíquico a circular e ser cuidado também nos espaços da Unidade por todos os profissionais que compõem aquele serviço. Isso não compareceu desta forma para os outros psicólogos, certamente, pelo fato deles, de certo modo, serem favorecidos pelos pressupostos da Estratégia de Saúde da Família, que, em sua proposta de reorganização da atenção básica, prioriza as ações de proteção e promoção à saúde dos indivíduos e da família, tanto adultos, quanto crianças, sadios ou doentes, de forma integral e contínua. Para tanto, por meio também do agente comunitário de saúde, mantém-se o elo necessário entre serviço e população, além desta estratégia estabelecer, como imprescindíveis, encontros sistemáticos entre os profissionais que compõem este serviço, o que pode beneficiar a efetivação de um cuidado integral em saúde.

Além daquelas dificuldades anunciadas pelos psicólogos das duas Unidades que não funcionam na lógica da ESF, compareceu também a afirmativa de que esta condição - de não funcionar como ESF apresenta-se como desfavorável ao acompanhamento dos casos, bem como a manutenção das informações atualizadas sobre essas pessoas em sofrimento psíquico - trabalho realizado na ESF principalmente pelos agentes comunitários de saúde - tendo em vista também o pouco encontro entre os profissionais que compõem aquele serviço.

Nesse contexto, foi frequente entre os psicólogos destas Unidades a afirmativa de um trabalho voltado a um "atendimento ambulatorial no esquema mesmo de consultas individuais" (Profissional 4), contudo estes mesmos profissionais referem, também, em alguns momentos, por um esforço pessoal, conseguirem parcerias intersetoriais e interdisciplinares para o cuidado em saúde mental. Essas parcerias, segundo eles, às vezes, acontecem mesmo para facilitar o encaminhamento a outros serviços, mas, outras vezes, ocorrem, também - principalmente quando entre profissionais de uma mesma Unidade - para desmistificar a ideia de periculosidade da pessoa em sofrimento psíquico e assim ampliar as possibilidades de cuidado.

A Psicologia demonstra suas possibilidades de contribuição na atenção básica na medida em que opera transformações no modo dos outros profissionais também olharem o processo saúde-doença, trabalhando com um conceito ampliado de saúde, que assim, tem potência para atuar, a partir daquele contexto histórico e cultural, com todas as parcerias possíveis, pela integralidade do cuidado. Em relação a isto, Dimenstein (2001) traz a discussão à necessidade, principalmente no que diz respeito a este contexto, dos psicólogos incorporarem outras concepções de práticas profissionais, que incluam o sujeito-usuário como participantes ativos do processo de promoção à saúde. Isto implica romper com a "identidade profissional hegemônica vinculada à do psicoterapeuta” (p. 62), a qual sustenta uma prática isolada no campo da saúde coletiva, ainda predominante entre os profissionais psicólogos deste setor, que em sua grande maioria não foi preparado para atuar no campo da assistência pública à saúde.

Assim, alimentam-se as definições limitantes do público do que seja a prática psicológica, de modo que a demanda ao psicólogo, por parte da população e dos demais profissionais da Unidade de Saúde, continua focada nos atendimentos ambulatoriais individuais em detrimento de outras atividades coletivas que envolvam parcerias para as transformações sociais necessárias (Dimenstein, 2000). Todavia, a partir dos dados desta pesquisa, pudemos apreender que tais perspectivas e demandas puderam em parte ser revertidas por aqueles entrevistados que incluíram tais discussões na pauta das reuniões de equipe, pela certeza de seu papel de apoio à atenção básica. Vale destacar neste momento a importância desta clareza em relação a sua função na atenção básica, bem como o acompanhamento e avaliação de sua atuação, uma vez que é grande o "risco de se desvirtuar a proposta 
e de voltar ao antigo, conhecido e seguro modelo ambulatorial" (CFP, 2009, p. 46).

Os psicólogos da atenção básica que conseguiram afirmar este lugar também de apoiadores matriciais disseram conseguir contribuir mais para o propósito de um cuidado integral à saúde. No entanto, essa mudança no modo de demandar o psicólogo da atenção básica e de perceber a necessidade de um cuidado da pessoa em sofrimento psíquico por todos os profissionais da Unidade de Saúde requer um trabalho contínuo de afirmação destas outras possibilidades de atuação; tanto que os psicólogos entrevistados (que trazem tais conquistas) falam de suas insistentes abordagens, junto a equipe de saúde da família, no sentido de afirmar que as questões de saúde mental perpassam qualquer processo de construção de saúde, logo - independentemente de uma atenção psicológica - esse sujeito-usuário pode e deve ser cuidado por todos. Ainda assim, esses entrevistados afirmaram que a apreensão desta outra perspectiva de trabalho 'psi' se diferencia entre as equipes, de modo que tem aquelas que insistem em associar exclusivamente a saúde mental à Psicologia.

Eu tento fazer eles verem que tudo é saúde, que não tem saúde sem saúde mental, para que eles andem sem a bengala da Psicologia. Outro dia, o CAPS pediu para marcar o matriciamento, aí eu só agendei, marquei com um, combinei com o outro. Aí uma das reuniões aconteceu, eu não pude participar, mas aconteceu e decidiram e tudo mais. Achei ótimo, maravilhoso. É isto o trabalho. Já a outra, mesmo eu falando que tinha grupo, não começou a reunião enquanto eu não cheguei. Aquilo assim: "a saúde mental é sua, você me colocou nesta fria, você não vai me deixar sozinha". Aí eu fiz o grupo, depois fui até lá e eu no final falei: "você viu, matriciamento é para a gente falar sobre as coisas, o que o fulano sabe, o que você sabe, o que o outro serviço sabe e a gente conversa junto para ter uma visão maior sobre o problema, não necessariamente a gente vai resolver os problemas, a gente vai pensar estratégias possíveis" (Profissional 6).

Este psicólogo parece atuar pela possibilidade de uma prática integrativa, interativa e dialógica, com vistas à construção de um projeto coletivo de cuidado, que destaca a singularidade e a complexidade de cada situação que se apresenta no cenário da atenção básica, em suas dimensões: sociais, políticas, econômicas, biológicas e subjetivas. Consequentemente, configura-se um contexto favorável à atuação sob a lógica do apoio matricial, no sentido de suporte técnico-pedagógico à atenção básica para a construção de conhecimentos e práticas de produção de vida no território. Assim, alguns entrevistados conseguem visualizar avanços no cuidado em saúde mental em relação ao período em que não se tinha tal prática no município, como, por exemplo, no que diz respeito à apropriação dos médicos de família pelo cuidado as pessoas em sofrimento psíquico e a consequente organização de algumas equipes de saúde para tal atuação.

Esses psicólogos que se colocaram, desde o início de sua inserção na Unidade, como matriciadores das equipes de saúde, mencionaram conseguir realizar atividades grupais, atendimentos e visitas domiciliares em conjunto com outros profissionais da US, bem como participarem das reuniões das equipes, contribuindo na discussão dos casos de pessoas em sofrimento psíquico que requisitam cuidados pelos vários profissionais do serviço, o que favorece 0 acompanhamento destas situações que envolvem o olhar da saúde mental. Nesse sentido, um psicólogo relatou uma experiência de aproximação interdisciplinar importante para este cuidado.

Foi feito aqui um trabalho conjunto, muito legal, de diminuição de uso de benzo, foi um movimento também com os funcionários, com os enfermeiros, com os médicos, da questão da desmedicalização, da questão do desmame do benzo mesmo. Isto foi uma questão de apoio matricial, de desmedicalização, a gente foi lá no CAPS, duas médicas, a farmacêutica, o enfermeiro, eu, para conversarmos com a psiquiatra de lá sobre a questão do benzo, aí ela deu umas orientações, explicou. Foi um trabalho de total parceria (Profissional 1).

Trata-se de um projeto construído a partir da realidade daquele território que requisitou parcerias diversas para sua efetivação, uma vez que se refere a uma situação-problema que vai além de uma simples suspensão de medicamento, e exige necessariamente a mudança da escuta e do olhar dos prescritores e 
demais profissionais de saúde diante do sofrimento dos usuários; além da construção de outras respostas no território para aquela situação, por meio de ações interdisciplinares e intersetoriais, já que estes sofrimentos falam também, muitas vezes, das condições gerais de vida, desfavoráveis a promoção à saúde.

Nessa perspectiva de ação, outro psicólogo afirma seu papel de provocar a equipe na direção de garantir o acesso e o cuidado das pessoas em sofrimento psíquico também pela Unidade de Saúde.

Tento fazer isto como psicóloga, mexer, acho que é isto, a ideia do movimento, a ideia de movimentar estas reuniões, movimentar estas propostas, para ver se as pessoas se implicam no trabalho. Eu acho que é processo, se atende neste ponto? Não sei, mas acho que é uma tentativa, uma proposta de movimentar para ver se há esta implicação dos profissionais das Unidades de ver também a saúde mental e cuidar dentro daquilo que cada um pode oferecer (Profissional 6).

O psicólogo na atenção básica tem também essa importante função de articular, mobilizar e sensibilizar as equipes de saúde da família para a inclusão desta temática na lista de prioridades de cuidado, tendo em vista um vasto histórico de restrição de tratamento das pessoas em sofrimento psíquico às especialidades. Assim, a proposta de matriciamento em saúde mental afirma mais uma vez sua relevância, pela sua potência em fazer circular pela Unidade de Saúde este saber especializado, compondo o campo de saber da saúde coletiva para um cuidado efetivamente integral. Neste contexto, os psicólogos pontuaram a importância também do suporte do gestor da Unidade para que este trabalho aconteça de modo efetivo e eficaz: "Quando o diretor apoia, isto é uma coisa muito importante, a gente consegue fazer um trabalho bacana de parceria, mas senão, fica difícil. A primeira Unidade que eu fui, a diretora tinha muita resistência, então foi muito difícil, ela boicotava, sabotava, o que ela podia" (Profissional 5).

Por outro lado, outro entrevistado, que também falou desta função do psicólogo na atenção básica de levar a discussão da saúde mental aos outros profissionais da Unidade, entende esta tarefa como um trabalho de cobrança em relação aos demais profissionais.
Acaba que o psicólogo da ponta fica com o encargo de cobrar coisas dos seus colegas, sobre os quais você não tem gestão, por isto que eu acho que tinha que vir uma determinação de cima para baixo: "vocês têm que organizar o serviço", tem que envolver, assistente social, enfermeiro, médico, farmacêutico querendo ou não querendo, porque o trabalho, não pode ter esta coisa de não quero trabalhar com saúde mental e nada acontece, não quer trabalhar e não trabalha (Profissional 3).

Nessa perspectiva, este psicólogo reconhece sua atuação como voltada à direção, ao planejamento e à avaliação do serviço, de modo que cabe a ele verificar os casos que precisam de atendimento psiquiátrico e fiscalizar se os usuários com algum sofrimento psíquico estão fazendo uso regular da medicação, assim sua atividade parece orientar-se a partir da prescrição médica psiquiátrica.

A gente tem ali coisa de direção, planejamento, avaliação do trabalho. A gente vê o caso se precisa ir para o psiquiatra, se está tomando o remédio, por exemplo, é questão da saúde mental, está em crise é PA mesmo, vai falar comigo? Eu não dou remédio. Eu não sou médica. Estes dias mesmo veio uma mãe: 'mas você marcou a minha filha para daqui a dois meses', eu olhei: 'oh, sua filha foi no psiquiatra e ele nem deu medicação, eu avalio então que ela pode esperar dois meses' (Profissional 3).

Este psicólogo destaca em sua fala a necessidade de políticas afirmativas, que assegure o cuidado à pessoa em sofrimento psíquico por todos os profissionais da atenção básica, tendo em vista o histórico de exclusão deste sujeito também neste nível de atenção. Contudo, defendemos que isto não deve significar uma ação impositiva e hierarquizada, pois como os próprios resultados deste estudo apresentaram, a cobrança e obrigação percebida e anunciada por alguns profissionais em relação ao matriciamento em saúde mental, por exemplo, não gerou implicação, mas resistência dos trabalhadores à proposta, a qual pretende prioritariamente contribuir para a integralidade do cuidado. Inclusive, este mesmo psicólogo, ao relatar suas atividades de grupos terapêuticos, refere dificuldade em agregar outros profissionais a compor 
a coordenação destes espaços grupais, por uma rejeição, por parte dos demais profissionais, a aceitarem suas solicitações. Neste contexto, destacamos o trabalho em saúde mental, incluindo o matriciamento desta temática, como processual, que envolve ação de desmitificação de alguns preconceitos, de convencimento/sedução e acolhimento dos demais profissionais de saúde em seus medos e entendimentos variados, na direção de garantir que todos possam contribuir para este cuidado com aquilo que tem de recurso pessoal e profissional.

Para Carvalho (2005), é o envolvimento desses profissionais no pensar processualmente estas propostas de ação, de acordo com a sua realidade e aquela que se apresenta em seu território, que faz com que eles se sintam potentes a contribuir pela construção destes territórios vivenciais prazerosos, que envolvem relações de confiança e solidariedade, combinando trabalho inventivo com compromisso social, para um cuidado efetivamente integral.

\section{Considerações Finais}

Foi possível apreender, a partir dessa pesquisa, que o entendimento compartilhado pelos profissionais de saúde sobre matriciamento orientaram a atuação dos psicólogos inseridos na atenção básica e as práticas dos demais profissionais em relação à saúde mental. Aqueles psicólogos que, juntamente aos demais profissionais, trouxeram, por exemplo, a concepção de que o matriciamento é uma prática baseada em relações de cobranças e hierarquias, sustentaram uma atuação voltada unicamente ao atendimento ambulatorial em Psicologia, de modo que o psicólogo se manteve quase que exclusivamente responsável pelo cuidado em saúde mental. Por outro lado, aqueles que partilharam da concepção de que o apoio matricial refere-se ao compartilhamento de saberes e práticas em saúde mental, conseguiram construir uma atuação integrativa a partir de parcerias firmadas para um cuidado mais integral.

Pode-se afirmar que têm coexistido, nas Unidades de Saúde, práticas que, apesar de serem entendidas como de Apoio Matricial, se diferenciam nos conceitos de mundo, sujeito e saúde que as embasam e na própria concepção que carregam sobre matriciamento em saúde mental. Os entendimentos trazidos nessa pesquisa pelos entrevistados por vezes estiveram sustentados em uma perspectiva de saúde como ausência de doença, ao discutir, por exemplo, a resolutividade do apoio matricial, ou ainda ao trazer a ideia de compartimentalização dos sujeitos, por conceber que cabe unicamente ao psicólogo os cuidados em saúde mental. Em outras ocasiões, fez-se presente uma perspectiva mais ampliada de saúde, em que foram propostas alternativas de cuidado a partir da realidade daquele território, pela desmedicalização e pela não fragmentação dos sujeitos nas questões que circundam sua mente e seu corpo.

Apesar dessa variedade de entendimentos e práticas envoltas ao apoio matricial em saúde mental, predominaram nessa pesquisa concepções a respeito do matriciamento que não contribuem para sua efetivação naquilo que se propõe a nível teórico, conforme trazido neste texto por Campos (1999) e Campos e Domitti (2007), o que implica em um distanciamento da perspectiva de articulação interdisciplinar e intersetorial por uma clínica ampliada. Tem-se todo um contexto de associação exclusiva dos 'psi' à saúde mental, de fragmentação do cuidado em especialidades, de relações hierarquizadas entre especialistas e generalistas, que reforçam a manutenção de práticas individualizadas e obstaculizam a efetivação de parcerias para a promoção à saúde. No entanto, também são inegáveis as contribuições trazidas pelo apoio matricial à saúde mental, mesmo diante das dificuldades de se efetivar nessa realidade, em toda a sua potencialidade. Assim como trazido por outros atores (Figueiredo, 2006, Figueiredo, \& Campos, 2009) que discutem a temática, o matriciamento efetivado nesse município vem contribuindo para o cuidado em saúde mental na medida em que outros profissionais, para além do profissional 'psi', têm se apropriado e se inserido como também responsáveis pelo cuidado em saúde mental. A atenção básica vem reconhecendo as pessoas em sofrimento psíquico como sujeitos de direito, que devem igualmente ser cuidadas nesse espaço da Unidade de Saúde, desmitificando ideias relacionadas à periculosidade e irrecuperabilidade desses também usuários de saúde, entre os próprios profissionais da atenção básica.

Em relação a essas contribuições que o matriciamento vêm trazendo para saúde mental, tem-se o exemplo trazido neste texto de construção de ação voltada à "diminuição do uso de benzo", em que o psicólogo foi demandado a atuar junto à equipe da atenção básica de outro modo que não unicamente direcionado ao atendimento individual psicoterápico e assim foi possível construir, a partir da necessidade 
daquele território, articulações interdisciplinares para a efetivação de um cuidado efetivo, condizente à realidade das pessoas em uso abusivo de benzodiazepínico.

Diante das potencialidades e dificuldades apontadas neste texto, relacionadas à efetivação do matriciamento em saúde mental, indicamos que essa proposta de trabalho e as relações suscitadas por ela entre profissionais, serviços, gestores e usuários sejam insistentemente e constantemente colocadas em análise, no sentido de problematizar: estamos atuando no sentido de reforçar a ideia de que cabe a cada um a sua parte no tratamento em saúde? Ou estamos nos envolvendo na invenção de uma saúde que requer lutas coletivas para um cuidado integral? Trata-se de uma estratégia em construção, a qual requer um trabalho contínuo de afirmação de suas potencialidades em contribuir para a construção de um sistema de saúde de qualidade em sua proposta de cuidado integral também às pessoas que vivenciam a experiência de sofrimento psíquico por todos os profissionais de saúde, independente de formação na área 'psi'.

\section{Referências}

Araújo, J. N. G., \& Carreteiro, T. C. (Orgs.). (2001). Cenários sociais e abordagem clínica. São Paulo, SP: Escuta. Bardin, L. (1988). Análise de conteúdo. Lisboa: Ed. 70. Brasil. (2003). Ministério da Saúde. Saúde mental e atenção básica: o vínculo e o diálogo necessários. Brasília, DF: o autor.

Brasil. (2005). Ministério da Saúde. Reforma psiquiátrica e política de saúde mental no Brasil - Conferência Regional de Reforma dos Serviços de Saúde Mental: 15 anos depois de Caracas. Brasília, DF: o autor.

Brasil. (2008). Ministério da Saúde. HumanizaSUS: documento base para gestores e trabalhadores do SUS (4a.ed.). Brasília, DF: o autor.

Camargo-Borges, C., \& Cardoso, C. L. (2005). A psicologia e a estratégia saúde da família: compondo saberes e fazeres. Psicologia e Sociedade, 17(2), 26-32. doi:10.1590/S0102-71822005000200005

Campos, G. W. S. (1999). Equipes de referência e apoio especializado matricial: um ensaio sobre a reorganização do trabalho em saúde. Ciência e Saúde Coletiva, 4(2), 393-403. doi:10.1590/S1413-81231999000200013

Campos, G. W. S., \& Domitti, A. C. (2007). Apoio matricial e equipe de referência: uma metodologia para gestão do trabalho interdisciplinar em saú-
No mais, a partir dessa pesquisa, é possível indicar ainda a necessidade de colocar em discussão, junto à gestão, os matriciadores, as equipes da atenção básica e os psicólogos atuantes nas Unidades de Saúde, o papel da Psicologia nesse nível de atenção, para que assim os psicólogos possam afirmar também o seu lugar de atuação pela promoção à saúde ao se estabelecer parcerias para a proposição de ações condizentes com as necessidades locais, que promovam uma mudança na produção social da demanda, atualmente voltada, predominantemente, ao consumo desenfreado de medicamentos e de atendimentos especializados em saúde mental para situações-problema, por vezes, coletivas, que ultrapassam a governabilidade de ação de um único setor. Como trazido por Franco e Merhy (2005, p. 14) “[...] é necessário ter um processo que procure construir novas bases produtivas para a saúde, baseadas no agir cotidiano dos sujeitos, tendo como pressuposto modelos centrados nos usuários, respeitando sua singularidade, atuando como produtores do cuidado integral à saúde".

de. Cadernos de Saúde Pública, 23(2), 399-407. doi:10.1590/S0102-311X2007000200016

Carvalho, S. R. (2005). Saúde coletiva e promoção da saúde: sujeito e mudança. São Paulo, SP: Hucitec.

Conselho Federal de Psicologia - CFP. (2009). A prática da psicologia e o núcleo de apoio à saúde da família. Brasília, DF: o autor.

Dimenstein, M. (2000). A cultura profissional do psicólogo e o ideário individualista: implicações para a prática no campo da assistência pública à saúde. Estudos de Psicologia (Natal), 5(1), 95-121. doi:10.1590/S1413-294X2000000100006

Dimenstein, M. (2001). O psicólogo e o compromisso social no contexto da saúde coletiva. Psicologia em Estudo, 6(2), 57-63. doi:10.1590/S1413-73722001000200008

Ferreira Neto, J. L. (2008). Psicologia e saúde mental: três momentos de uma história. Saúde em Debate, 32(78/79/80), 18-26. Recuperado de http://www. pucminas.br/documentos/tresmomentos.pdf

Ferreira Neto, J. L. (2010). A atuação do psicólogo no SUS: análise de alguns impasses. Psicologia: Ciência e Profissão, 30(2), 390-403. doi:10.1590/S1414-98932010000200013

Figueiredo, M. D. (2006). Saúde mental na atenção básica: um estudo hermenêutico - narrativo sobre 
o apoio matricial na rede SUS - Campinas (SP) (Dissertação de mestrado). Universidade Estadual de Campinas, Campinas, SP.

Figueiredo, M. D., \& Campos, R. O. (2009). Saúde mental e atenção básica à saúde: o apoio matricial na construção de uma rede multicêntrica. Saúde em Debate, 32(78/79/80), 143-149.

Franco, T. B., \& Merhy, E. E. (2005). Produção imaginária da demanda. In: R. Pinheiro, \& R. A. Mattos (Org.), Construção social da demanda. Rio de Janeiro, RJ: IMS/UERJ-CEPESC-ABRASCO.

Freire, F. M. S., \& Pichelli, A. A. W. S. (2010). Princípios norteadores da prática psicológica na atenção básica: em busca da integralidade. Psicologia: Ciência e Profissão, 30(4), 840-853. doi:10.1590/S1414-98932010000400013

Lourau, R. (2004). Implicação: um novo paradigma? In: S. Altoé (Org.), René Lourau: analista institucional em tempo integral (pp. 246-258). São Paulo, SP: Hucitec.

Lussi, I. A. O., Pereira, M. A. O., \& Pereira Junior, A. (2006). A proposta de reabilitação psicossocial de Saraceno: um modelo de auto-organização? Revista Latino-Americana de Enfermagem, 14(3), 448-456. doi:10.1590/S0104-11692006000300021

Mattos, R. A. (2006). Os sentidos da integralidade: algumas reflexões acerca de valores que merecem ser defendidos. In: R. Pinheiro, \& R. A. Mattos, R. A. (Org.), Os sentidos da integralidade na atenção e no cuidado à saúde (pp. 639-644). Rio de Janeiro, RJ: UERJ.

Nicácio, M. F. (2003). Utopia da realidade: contribuições da desinstitucionalização para a invenção de serviços de saúde mental (Tese de doutorado). Universidade de Campinas, Campinas, SP.

Pedroso, R. T., \& Vieira, M. E. M. (2009). Humanização das práticas de saúde: transversalizar em defesa da vida. Interface (Botucatu), 13(1), 695-700. doi:10.1590/S1414-32832009000500020

Romanholi, A. C. (2004). Na corda bamba: Reforma Psiquiátrica e Saúde Mental na Atenção Primária (Dissertação de mestrado). Universidade Federal do Espírito Santo, Vitória, ES.

Rotelli, F. (1990). A instituição inventada. In F. Nicácio (Org.), Desinstitucionalização. São Paulo: Hucitec.

Spink, M. J. P. (Org). (2007). A psicologia em diálogo com o SUS: prática profissional e produção acadêmica. São Paulo, SP: Casa do Psicólogo.
Starfield, B. (2002). Atenção primária: equilíbrio entre necessidades de saúde, serviços e tecnologia. Brasília, DF: Unesco.

Stotz, E. N., \& Araújo, J. W. G. (2004). Promoção da saúde e cultura política: a reconstrução do consenso. Saúde e Sociedade, 13(2), 5-19. doi:10.1590/S0104-12902004000200002

Teixeira, R. R. (2005). Humanização e atenção primária à saúde. Ciência e Saúde Coletiva, 10(3), 585-598. doi:10.1590/S1413-81232005000300016

Vitória. (2014). Secretaria de Saúde. Programa de melhoria do acesso e da qualidade dos serviços de saúde do município de Vitória (PMAQ Vitória) e Incentivo de Desempenho Variável (IDV). Vitória, ES: o autor.

\section{Alexandra Iglesias}

Professora Adjunta do Departamento de Psicologia da Universidade Federal do Espírito Santo, Vitória - ES. Brasil.

E-mail: leiglesias@gmail.com

\section{Luziane Zacché Avellar}

ProfessoraAssociada II do Departamento de Psicologia Social e do Desenvolvimento e do Programa de PósGraduação em Psicologia da Universidade Federal do Espírito Santo, Vitória - ES. Brasil.

E-mail: luzianeavellar@yahoo.com.br

Endereço para envio de correspondência:

Prédio Lídio de Souza, sala 24, Avenida Fernando

Ferrari, 514

Goiabeiras, Vitória-ES, CEP -29075-910 Brasil

Recebido: 01/10/2014

Reformulação: 17/06/2015

Aprovado: 29/04/2016

Received: 10/01/2014

Reformulated: 06/17/2015

Approved:04/29/2016

Recibido: 01/10/2014

Reformulado: 17/06/2015

Aceptado: 29/04/2016 
Como citar: Iglesias, A., \& Avellar, L. Z. (2016). As contribuições dos psicólogos para o matriciamento em saúde mental. Psicologia: Ciência e Profissão, 36(2): 364-379. doi:10.1590/1982-3703001372014

How to cite: Iglesias, A., \& Avellar, L. Z. (2016). The psychologist's contribution to the matrix support in mental health. Psicologia: Ciência e Profissão, 36(2): 364-379. doi:10.1590/1982-3703001372014

Cómo citar: Iglesias, A., \& Avellar, L. Z. (2016). Las contribuciones del psicólogo para el apoyo matriz en salud mental. Psicologia: Ciência e Profissão, 36(2):364-379. doi:10.1590/1982-3703001372014 